\title{
REVIEW
}

\section{EVALUATION AND TREATMENT OF THE OVERACTIVE BLADDER}

Eric S. Rovner, Cristiano M. Gomes, Flavio E. Trigo-Rocha, Sami Arap and Alan J. Wein

RHCFAP/3067

ROVNER ES et al. - Evaluation and treatment of the overactive bladder. Rev. Hosp. Clín. Fac. Med. S. Paulo 57(1):39-48, 2002.

The overactive bladder is characterized by symptoms of frequency, urgency, and urge incontinence, substantially affecting the quality of life of millions of people throughout the world. The symptoms are associated with significant social, psychological, occupational, domestic, physical, and sexual problems. Despite the considerable impact of this condition on quality of life, sufferers are often unwilling to discuss their problem with family members or health care professionals. This situation is unfortunate, for much can be done to alleviate the symptoms of this distressing condition. It is therefore of utmost importance that medical education about symptoms of the overactive bladder and other related problems be improved to help health care professionals identify and treat patients who will benefit from therapy. This article reviews current thinking regarding definition, epidemiology, quality of life effects, evaluation, and management of the overactive bladder.

DESCRIPTORS: Bladder diseases. Urinary incontinence. Urodynamics.

The overactive bladder $(\mathrm{OAB})$ is a highly prevalent disorder that impacts the lives of millions of people worldwide. Despite its high prevalence, most sufferers do not seek medical attention and are unaware that $\mathrm{OAB}$ is treatable. Notwithstanding the recently increased medical and media attention given to it in many countries, OAB remains vastly underreported and its sufferers untreated. The purpose of this manuscript is to update the definition of OAB for the clinicians involved with the treatment of patients with voiding dysfunction and to present a clinically relevant approach for the evaluation and treatment of this disorder. Further, expanded information may be found in recently published reviews and conference proceedings ${ }^{1-3}$.

\section{SYMPTOMS AND DEFINITION}

Typical symptoms of the overactive bladder include an increased number of micturitions (frequency-emptying the bladder more often than 8 times a day), a strong and sudden desire to void (urgency), and if the urge cannot be suppressed, urinary urge incontinence. Symptoms of OAB presumably occur because the detrusor muscle is overactive and contracts inappropriately during the filling phase $\mathrm{p}^{4-7}$. Frequency can occur as a result of reduced functional bladder capacity. It can also be

From the Division of Urology of the Department of Surgery, Hospital das Clínicas, Faculty of Medicine, University of São Paulo and University of Pennsylvania, School of Medicine. caused at least partly by a coping mechanism adopted by patients to avoid leakage of large volumes of urine by maintaining a relatively low volume in the bladder. When patients experience a sensation of urgency, they may leak urine if they are unable to reach the toilet quickly or if the sensation of urgency is very strong. The amount of urine lost may be large, since the bladder may empty completely. Sleep may be disturbed, since the need to void may be experienced during the night. Nighttime frequency and nocturnal enuresis (bedwetting) is often particularly disruptive. When bladder contraction occurs without warning and sensation is absent, as in a patient with neurologic disease such as spinal cord injury, the condition is referred to as reflex incontinence. 
The definition of the overactive bladder by the International Continence Society (ICS) is based on urodynamics and is currently being reevaluated $^{6,8,9}$. The ICS definition includes the presence of involuntary bladder contractions that are provoked during a filling cystometrogram while the patient is attempting to suppress them $^{8}$. The reasons why the definition must be changed are twofold: (1) on a worldwide basis, it is impractical, unnecessary, and impossible for all patients with symptoms of bladder overactivity to be treated by urologists and undergo urodynamic studies, a necessary step in the diagnosis of this condition based on the present definition of the ICS, and (2) urodynamic studies can have both false-positive and false-negative results, and these mistaken test results can include normal patients in the diagnosis of bladder overactivity or exclude patients who clearly have overactive bladder symptoms based on a false-negative urodynamic study.

It should be possible to define bladder overactivity based on symptoms ${ }^{3}$. A reasonable symptom-based definition would be a condition referring to the symptoms of frequency and urgency, with or without urge or reflex incontinence, when appearing in the absence of local pathological factors (e.g. cancer, carcinoma-in-situ, urinary tract infection, stones, interstitial cystitis) as explanations for these symptoms. Patients with overactive bladder can include individuals with and without a possible neurologic cause for their symptoms. Urodynamic bladder overactivity would then describe the phenomenon of involuntary bladder contractions causing symptoms or signs. The distinction between detrusor hyperreflexia and instability is not as clear-cut as it once seemed, however. Does an individual with involuntary bladder contractions with no gross neurological signs or symptoms but with a cerebral imaging abnormality have hyperreflexia or instability? Does it matter?

\section{PREVALENCE}

It is difficult to estimate the true prevalence of bladder overactivity for two reasons: (1) Despite the considerable impact of bladder storage symptoms on quality of life, many patients never seek medical help and are thus uncounted; (2) There have been very few epidemiologic surveys carried out on the symptoms of urgency and frequency alone without incontinence. Surveys on the prevalence of urinary incontinence have been done, and estimates of the prevalence of bladder overactivity have been obtained by adding together the fraction of urge incontinent patients to the number of those with mixed incontinence ${ }^{6,9,10}$. Thus, the most prevalent figures that are available significantly underestimate the extent of the problem. A recent survey has found that the vast majority of people with chronic, bothersome symptoms of bladder overactivity complained of frequency and urgency, while only a third complained of urge incontinence ${ }^{11}$. The survey found that the total prevalence of $\mathrm{OAB}$ within the general population aged 40 years and over ranged from $12 \%$ to $22 \%$ in a sample of some 17000 people in $6 \mathrm{Eu}-$ ropean countries. It demonstrated that the risk of developing $\mathrm{OAB}$ increases with age. In the group of people 75 years and older, the prevalence ranged between $30 \%$ and $40 \%{ }^{11}$. Another problem that one encounters is exactly how to define urgency and frequency. For instance, if one defines frequency as simply voiding over 8 times per day, one will conclude that an incredible proportion of the world's population has overactive bladder. Furthermore, most of us experience significant urgency on one occasion or another, but it is not a chronic problem for us. Thus, the way that questions are asked regarding frequency and urgency makes a great difference with respect to reported prevalence.

\section{QUALITY OF LIFE; SOCIAL COSTS}

Urinary incontinence is associated with reduced levels of social and personal activities, increased psychological distress, and overall decreased quality of life (QOL) as measured by numerous indices ${ }^{12-16}$. Urinary incontinence is, however, only one aspect of OAB. Little data exists on the QOL impact of $\mathrm{OAB}$ in general or of urgency and/or frequency without incontinence ${ }^{17}$.

Emerging studies and studies in progress have shown that patients with OAB do suffer significantly poorer QOL than an age matched population $^{11,18}$. Those with OAB have been found to experience a lower QOL in the social and functional domains than diabetics. Other studies have shown that the QOL of patients with symptoms caused by the overactive bladder is more adversely affected than that of stress incontinence sufferers. This finding presumably reflects the differences in the symptoms experienced. Compared with stress incontinence, the overactive bladder is harder to predict, is more likely to disrupt sleep and daily activities, and more often leads to the loss of large volumes of urine ${ }^{14,19}$.

The overactive bladder and stress incontinence are problems that both sufferers and their physicians often fail to discuss. In a survey conducted in the UK, it has been shown that although approximately half of all sufferers would welcome some form of treatment, there is a reluctance to seek help ${ }^{11}$. Only one-third of regularly incontinent women discuss their problem with a nurse or primary care physician. 
Up to two-thirds of patients first seeking medical advice have had their symptoms for over 2 years. The reasons cited for this marked reluctance to seek help include low expectations of treatment and being too embarrassed.

The medical profession has often done little to dispel patients' common misconceptions about the condition. Research in this area has shown that although the majority of patients who discuss their condition with their primary care physician feel that they are treated sympathetically, $30 \%$ of those who discuss their problems with a health care professional receive no assessment and about $80 \%$ are not examined. Dismissing incontinence and related symptoms as minor ailments is misguided.

These symptoms can be the cause of great discomfort, shame, and loss of confidence, causing withdrawal from social life and affecting physical and mental health. In addition to the negative impact on the quality of life of those affected, a considerable financial burden is placed on society as a result of neglecting to diagnose and treat the condition $^{20}$. Studies of health care costs in the USA and Sweden estimate that urinary incontinence accounts for at least $2 \%$ of the national health care budgets ${ }^{11}$. Wagner and $\mathrm{Hu}$ estimated that the societal cost of incontinence for individuals in the USA aged 65 years and older in 1995 was a staggering 26.3 billion dollars ${ }^{21}$.

\section{PATHOPHYSIOLOGY}

Ultimately, whatever the primary cause of $\mathrm{OAB}$, the mechanism for bladder overactivity must be either neurogenic or myogenic ${ }^{22,23}$. The central nervous system mechanisms controlling the lower urinary tract are organized in the brain and spinal cord as simple on-off switching circuits under voluntary control. Damage to central pathways that are normally inhibitory (stroke, Parkinson's disease, multiple sclerosis, spinal cord injury, etc.) or sensitization of peripheral afferent terminals in the bladder can unmask primitive voiding reflexes that trigger bladder overactivity. This neurogenic basis is fully explored by deGroat ${ }^{23}$. Brading summarizes evidence for myogenic basis for $\mathrm{OAB}^{22}$. She describes spontaneous contractile (electrical) activity in detrusor strips from all species that is myogenic (originating in the muscle itself) but that fails to produce fused tetanic contractions because of poor electrical coupling between bladder smooth muscle cells. Precipitating factors such as bladder outlet obstruction can cause a partial denervation of smooth muscle, leading to a state of decreased responsiveness to activation of intrinsic nerves but supersensitivity to contractile agonists and direct electrical activation ${ }^{24-26}$. Spontaneous activity increases, and there is an increase in cell-to-cell electrical coupling. Filling, under these circumstances, could cause synchronous activation of the smooth muscle of the bladder wall and an increase in intravesical pressure. The most plausible situation for this type of phenomenon to occur would be in the male with bladder outlet obstruction, a condition in which $50 \%$ of affected individuals exhibit detrusor instability ${ }^{27-30}$. Each theory has its proponents, and doubtless, neither can account for all instances of OAB. It is often difficult to separate neurogenic and myogenic origin, and often they seem to be interconnected and complementary.

\section{EVALUATION}

Identifying patients with lower urinary tract symptoms caused by an $\mathrm{OAB}$, and differentiating between $\mathrm{OAB}$ and other types of urinary incontinence (i.e. stress incontinence, etc) is paramount to selecting appropriate treatment for the individual patient. National and international urological societies recommend that the initial evaluation should include, at a minimum (1) an assessment of the patient's symptoms; (2) physical examination; and (3) urinalysis ${ }^{31,32}$. A holistic approach should be employed, in which confounding conditions are identified and addressed. Once urinary tract infection has been excluded, it is possible in most cases to establish a working diagnosis based on the patient's description of symptoms and initiate therapy. In some patients, particularly those with symptoms of difficulty emptying, it may be desirable to measure post-void residual urine by catheterization or ultrasound to exclude incomplete bladder emptying as a cause of the patient's symptoms. In cases where there is uncertainty regarding the diagnosis, more advanced investigations, such as urodynamic assessment and/or cystoscopy should be carried out.

Symptom Assessment. When taking the patient's history, the aim is to both make a working diagnosis and to assess the impact of the symptoms on the patient's quality of life. As discussed previously, the typical symptoms of OAB include frequency, urgency, and urge incontinence. However, symptoms are not always diagnostic. Patients with stress incontinence, for example, may void frequently in an attempt to avoid leakage, since this condition is generally worse when the bladder is full. A careful history of the condition, with special emphasis on onset, progression/regression, response/nonresponse to treatments, is valuable. The use of a diagnostic aid is sometimes helpful for distinguishing between the symptoms of $\mathrm{OAB}$ and stress incontinence (Table 1). However, these two conditions often coexist $^{9}$. Symptoms of bladder overactivity can, however, be treated successfully in women with mixed incontinence symptoms. The review of 
Table 1 - Differentiating OAB from stress incontinence (After Abrams and Wein, 1998) ${ }^{11}$.

\begin{tabular}{|c|c|c|}
\hline SYMPTOMS & Overactive Bladder & Stress Incontinence \\
\hline $\begin{array}{l}\text { Urgency (strong, sudden } \\
\text { desire to void) }\end{array}$ & Yes & No \\
\hline Frequency with urgency & Yes & Rarely \\
\hline $\begin{array}{l}\text { Leaking during physical } \\
\text { activity e.g., coughing, } \\
\text { sneezing, lifting, etc. }\end{array}$ & No & Yes \\
\hline $\begin{array}{l}\text { Amount of urinary leakage } \\
\text { with each episode of incontinence }\end{array}$ & $\begin{array}{l}\text { Large } \\
\text { if present }\end{array}$ & $\begin{array}{l}\text { Usually } \\
\text { small }\end{array}$ \\
\hline $\begin{array}{l}\text { Ability to reach the toilet in } \\
\text { time following an urge to void }\end{array}$ & $\begin{array}{l}\text { No or } \\
\text { just barely }\end{array}$ & Yes \\
\hline $\begin{array}{l}\text { Nocturnal incontinence (presence of } \\
\text { wet pads or undergarments in bed) }\end{array}$ & Yes & Rarely \\
\hline Nocturia (waking to pass urine at night) & Usually & Seldom \\
\hline
\end{tabular}

symptoms should concentrate on factors potentially related to etiology (neurologic, metabolic, medications, etc).

Frequency of micturition, the sensation of urgency and leakage episodes can be assessed by patient recall at the time of interview, or by self-monitoring using a frequency/volume chart or voiding diary (Fig. 1). Self-monitoring on a daily basis, using a chart, is a simple and practical method of obtaining information on voiding behavior. The point in time and volume of all voids over a specified period, together with

subjective information regarding sensations of urgency and leakage episodes, are recorded in the individual's own environment under normal conditions. To quantitate the amount of urine loss, if incontinence exists, a variety of pad tests are available and can serve as a baseline for subsequent outcome assessment $^{33}$.

Physical Examination. Physical examination should ideally include an abdominal exam to exclude a distended bladder, a neurologic assessment of the perineum and lower extremities, a pel-

\begin{tabular}{|l|c|c|c|c|}
\hline \multirow{2}{*}{ Time } & \multicolumn{2}{|c|}{ Voiding Episodes } & \multicolumn{2}{c|}{ Leakage } \\
\cline { 2 - 6 } & Amount (ml) & $\begin{array}{c}\text { Associated with urge to } \\
\text { void? }\end{array}$ & $\begin{array}{c}\text { Circumstance (stress, urge, or } \\
\text { unaware*) }\end{array}$ & Amount** \\
\hline & & & & \\
\hline & & & & \\
\hline & & & & \\
\hline & & & & \\
\hline & & & & \\
\hline & & & & \\
\hline & & & & \\
\hline & & & & \\
\hline & & & & \\
\hline
\end{tabular}

*Stress incontinence is leakage when coughing, sneezing, or with physical activity; urge incontinence is leakage associated with a strong desire to void that cannot be suppressed, and unaware incontinence is leakage that is not perceived by the patient when it happens. ** large (soaked underwear), medium (damp), or small (few drops)

Figure 1 - Frequency/volume chart or voiding diary to be completed over a 24-hour period, preferably for 3 to 5 consecutive days. vic exam in women (looking especially for evidence of prolapse or hormonal deficiency), and a genital and prostate exam in men. In females, an assessment of anterior vaginal wall prolapse (i.e. urethral hypermobility) and a Marshall-Bonney test may be performed to exclude coexistent stress incontinence in those patients with symptoms of mixed urinary incontinence. In both sexes, digital rectal exam provides an opportunity to check ambient rectal tone, the integrity of the sacral reflex arc (e.g. anal wink, etc.), as well as to assess the patient's ability to perform a voluntary pelvic floor muscle contraction (i.e. "Kegel" exercise), which may be an important factor in deciding on appropriate therapy.

Urinalysis. Altered bladder sensation during urinary tract infections can cause symptoms similar to those of $\mathrm{OAB}$. Urine microscopy and culture are the diagnostic gold standard, but reagent strip testing of urine is a sensitive and cheaper screening method. Tumors of the lower urinary tract may likewise cause urgency, frequency, and urge incontinence. Hematuria merits further urologic investigation. Irritative symptoms may prompt a voided urine sent for cytology, which, if positive for tumor or dysplastic cells, should likewise mandate further urologic evaluation. Significant glucosuria or proteinuria should prompt further medical or nephrologic evaluation or referral.

Residual Urine Measurement. It is desirable to measure post-void residual urine in some patients, particularly in the elderly with voiding symptoms and/or recurrent or persistent urinary tract infections, in those with neurological disease and voiding dysfunction, and in those with symptoms that suggest poor bladder emptying. Ultrasound or catheterization may be used to measure the volume of urine remaining in the bladder after voiding with distinct advantages to each method $^{34,35}$. 
Other Studies. Urodynamic studies quantitate data referable to the activity of the bladder and bladder outlet during the filling/storage and emptying phases of micturition. This technique allows exact characterization of any voiding dysfunction as well as the demonstration of lower urinary tract obstruction and its secondary effects on the bladder. A great deal of information regarding the function of the lower urinary tract is readily available from a properly performed urodynamic study, but its interpretation should be made within the context of the patient's presenting symptoms. Clearly, not all patients presenting with complaints of the OAB require sophisticated or even simple urodynamics. These studies are generally reserved for patients with mixed symptomatology or those who have failed initial therapy.

Other studies including cystoscopy, measurement of serum PSA, serum chemistries, including creatinine and radiographic imaging, should be done in a selective and judicious manner when clinically indicated.

\section{MANAGEMENT}

Transient or reversible conditions that result in OAB-type symptoms should immediately be addressed. These will be readily identified from a properly performed history, physical examination, and initial evaluation as described previously (e.g. urinary infection, hormone deficiency, drug side effects, excessive urine output, fecal impaction, altered mental state). Appropriate treatment of other conditions that can contribute to or be associated with $\mathrm{OAB}$ (bladder outlet obstruction, vaginal prolapse, significant stress incontinence, diabetes) should always be considered, since therapy of these problems may often improve or alleviate symptoms completely.

Except in those cases where OAB is clearly secondary and reversible by correction of a primary cause (bladder outlet obstruction, etc.), one does not cure $\mathrm{OAB}$. One rebalances lower urinary tract function with the help of behavioral, pharmacologic, neurostimulatory, or surgical modalities. Actual management options for $\mathrm{OAB}$ are fairly easy to characterize and are designed to facilitate bladder filling/urine storage by decreasing contractility, increasing capacity, or decreasing sensation (Table 2). We will consider only some of these in detail and refer the reader to other sources for a more complete discussion and references ${ }^{1,2,36-41}$.

\section{Behavioral therapy}

This rubric includes: (1) patient education about lower urinary tract function; (2) fluid management; (3) bladder training or retraining; (4) pelvic floor physiotherapy; and (5) for physically or mentally challenged individuals, scheduled and/or prompted voiding. For the average community-dwelling individual, the aim of behavioral therapy is to help regain bladder control by increasing the effective capacity of the bladder and thereby reducing the symptoms of the overactive bladder. Keeping a record in the form of a frequency/volume chart, plays a central role in bladder training, as well as looking at the urine output in relation to the patient's fluid intake, which may need to be reduced. The patient is asked to gradually increase the intervals between voiding by maneuvers that inhibit the micturition reflex (i.e. pelvic floor exercise or "Kegel" exercises), resulting in a gradual increase in bladder capacity. These exercises are taught in such a way that patients can use this physiologic mechanism to inhibit an impending or beginning bladder contraction (micturition reflex). A properly timed "Kegel" exercise (voluntary contraction of the striated muscle of the pelvic floor) may have the dual benefit of increasing out-
Table 2 - Therapy to facilitate bladder filling and urine storage.

Inhibiting bladder contractility, decreasing
sensory input and/or increasing bladder
capacity
Behavioral therapy
Timed bladder emptying
Bladder training; biofeedback
Pharmacologic therapy
Anticholinergic agents
Musculotropic relaxants
Calcium antagonists
Potassium channel openers
Prostaglandin inhibitors
Beta-adrenergic agonists
Alpha-adrenergic antagonists
Tricyclic antidepressants
Dimethyl sulfoxide (DMSO)
Polysynaptic inhibitors
Therapy decreasing sensory input
Bladder overdistention
Electrical stimulation (reflex inhibition);
neuromodulation
Acupuncture
Interruption of Innervation
Central (subarachnoid block)
Sacral rhizotomy, selective sacral rhizotomy
Perivesical (peripheral bladder denervation)
Augmentation cystoplasty

let resistance as well as inhibiting the micturition reflex and sacral arc during an involuntary bladder contraction. Often patients are initially unable to "find" and voluntarily contract their pelvic floor effectively. Biofeedback and/or electrical stimulation may be quite beneficial as adjunctive measures in enabling patients to locate and utilize their pelvic floor in an effective manner. The frequency/volume chart is used throughout therapy in order to monitor its success. Initially, in some cases, it may be useful to ask the patient to void hourly by the clock. Once this is managed without leakage, the interval is increased by 15 minutes at a time, until the interval between voiding is between 2 and 4 hours.

Results with behavioral therapy are quite good. Fantl et al. recorded a 57\% reduction in incontinent episodes and a $54 \%$ reduction in the quantity of urine loss in older women ${ }^{42}$. The reduction in incontinence episodes was similar in patients with $\mathrm{OAB}$ and stress in- 
continence; the reduction in quantity of loss was better in OAB patients than those with stress incontinence. Fantl reviewed several studies and concluded that behavioral therapy for OAB resulted in complete resolution of symptoms in less than $15 \%$ of patients but a 50 to $75 \%$ reduction of symptoms in $50 \%{ }^{43}$. Behavioral therapy can be utilized by any health care professional. It is simple, inexpensive, and effective. It does, however, require patient and caregiver motivation and a time commitment ${ }^{14,44}$. It can and should be easily combined with other nonsurgical regimens.

\section{Pharmacotherapy}

Pharmacotherapy and behavioral therapy are the mainstays of treatment of OAB. Although there are multiple central and peripheral sites and mechanisms that can influence bladder function, few are clinically useful. The problems are: (1) how to affect bladder function without interfering with the function of other organ systems (uroselectivity) and (2) how to eliminate overactivity without disturbing normal micturition ${ }^{36}$. Multiple types of drug therapies are potentially useful for decreasing bladder contractility or decrease sensation, but antimuscarinic medication remains the most commonly prescribed treatment (Table $3)^{32,39,45}$.

Table 3 - Commonly utilized anticholinergic/antispasmodic preparations.

Anticholinergic agents
Hyoscyamine sulfate (Levsin)*
Propantheline bromide (Probantine)**
Tolterodine (Detrusitol)
Parasympathetic impulses travel to the bladder along the efferent fibers of the pelvic nerves. Contractions of the detrusor muscle are mediated mainly by muscarinic receptors. There are 5 known subtypes of these receptors. Muscarinic receptors are widely distributed throughout the body. However, it is the M-3 variety that is responsible for involuntary bladder contractions and for the emptying contraction of a normal micturition ${ }^{46}$.

Thus, most antimuscarinic therapy is primarily anti-M-3 based. Atropine is the reference anticholinergic compound; however, it is not readily absorbed from the GI tract and has the potential to cause significant adverse effects. Currently, there are many anticholinergic preparations available for the pharmacologic treatment of the OAB. Some of these pharmaceuticals have an additional and varying component of directacting smooth muscle relaxant properties (musculotropic smooth muscle relaxant or antispasmodic properties). Whether these agents exert their clinical effects primarily through an anticholinergic mechanism or by way of a direct action on smooth muscle is unknown. In addition, the molecular mechanism by which these direct-acting smooth muscle relaxants act is unknown, but it is generally felt to be somewhere metabolically distal to the muscarinic receptor, perhaps in altering the intracellular handling of calcium.
Antispasmodics (variable amounts of anticholinergic properties)

Oxybutinin chloride (Retemic, Incontinol, Urazol, Frenurin)

Oxybutinin chloride extended release (Ditropan XL)*

Dicyclomine hydrochloride (Bentyl)

Flavoxate hydrochloride (Genurin)

*Not available in Brasil

**Prepared under prescription in Brasil
Several recent reviews cover these medications and their effects on the lower urinary tract in more detai ${ }^{39,47}$. In patients with involuntary bladder contractions, anticholinergic agents will increase the volume to the first involuntary bladder contraction, decrease the amplitude of that contraction, increase bladder capacity, but will not change the "warning time". Thus, drug therapy must always be combined with behavioral therapy to achieve optimal results in $\mathrm{OAB}^{39}$.

The problem with current anticholinergics has been the incidence of side effects, particularly related to salivary gland secretion and bowel function, which are significant enough to cause the patient to discontinue taking the medication. In one study, it was estimated that only approximately $18 \%$ of patients remained on anticholinergic therapy for over 6 months ${ }^{48}$. Activation of the M-3 receptors is responsible for bladder contraction, but M-3 receptors are also responsible for salivary gland smooth muscle contraction and gut smooth muscle contraction. Receptor selectivity alone does not seem to be a terribly practical concept for developing new agents unless an agent preferentially inhibits bladder M-3 receptors over those of the salivary gland or gut. Tolterodine is a recently introduced agent that is not receptor specific but that is relatively tissue-specific, in the sense that it has a greater effect on bladder smooth muscle than on salivary gland smooth muscle. Oxybutynin is the most prescribed anticholinergic drug and appears to have the opposite profile. In trials to date, tolterodine has produced beneficial therapeutic effects equivalent to oxybutynin with significantly fewer adverse effects than currently used oxybutynin preparations ${ }^{49-51}$. Reductions in OAB incontinence episodes with anticholinergic therapy range from $40 \%$ to $70 \%$, with reductions in urinary frequency being statistically significant but numerically less ${ }^{49-51}$. 
Estrogen therapy has the potential for successful treatment of OAB symptomatology in postmenopausal women. Although there are multiple mechanisms by which estrogen might favorably affect lower urinary tract function, opinion is divided as to whether low dose local therapy or systemic therapy can per se ameliorate irritative lower urinary tract symptoms in the postmenopausal female ${ }^{52-55}$.

\section{Peripheral electrical stimulation}

Electrical stimulation has been used by some investigators with success ${ }^{56-59}$. Peripheral electrical stimulation is thought to act through a mechanism involving reflex inhibition of motor output to the bladder and by activating inhibitory sympathetic fibers. However, there are disclaimers. Reported results have been mostly in patients with urgency incontinence, since incontinence episodes are generally associated with involuntary bladder contractions (a measurable parameter) and since incontinence episodes themselves are relatively easy to quantitate. Vaginal, anal, and lower extremity electrodes have produced "cure" rates of as high as $20 \%$ and improvement rates as high as $50 \%$ to $60 \%^{56-59}$. Duration of therapy, duration and intensity of stimulus, ideal delivery modality, and other parameters are not standardized and vary considerably between institutions. Often, in series such as these (not just electrical stimulation), it is difficult to figure out exactly what "improvement" means, and for how long improvement lasts, and whether patients believe that, overall, their quality of life is significantly improved.

\section{Other therapies}

Bladder overdistention, transvaginal alcohol/phenol injections, and transvaginal dissection, such as the Ingelman-Sundberg procedure, are all forms of peripheral denervation/neurologic decentralization. Each has its advocates. Following the progression of the algorithm to this stage with unsuccessful results, and excluding sacral rhizotomy or dorsal ganglionectomy in patients other than spinal cord injury patients, the two modalities of therapy that remain are an implantable stimulator for neuromodulation and augmentation cystoplasty. Catheterization or urinary diversion can each be thought of as methods for circumventing the condition, not treating it ${ }^{47}$.

Neuromodulation is a term used to describe alteration of reflex pathways. Sacral nerve stimulation with an implantable stimulator has been used with success for urge incontinence ${ }^{60-63}$. This minimally invasive procedure is a 2-step process. Initially, the patient has percutaneous placement of a wire electrode into the $\mathrm{S} 3$ foramina alongside of the nerve root as an outpatient procedure. The wire is then attached to an external pulse generator, and the patient is sent home. If the patient has a suitable response after 3 days of therapy, a permanent implant is then scheduled. The surgery for the permanent implant involves an incision in the lower back with a wire advanced into the S3 foramina under direct vision. The wire is then tunneled around to the flank. A pulse generator is then placed into the subcutaneous tissues on the anterior abdominal wall. The pulse generator is connected to the previously placed wire as it is tunneled subcutaneously around the flank. The pulse generator can be programmed by an external device and magnet in a similar manner as for a cardiac pacemaker. Trials are still ongoing with this device (Interstim ${ }^{\circledR}$ ) for urge incontinence and other lower urinary tract dysfunctions.

Surgery may improve severe overactive bladder symptoms when more conservative management has failed. Augmentation cystoplasty refers to procedures that increase bladder capacity. In enterocystoplasty, a portion of bowel is removed from the fecal stream and is incorporated into the dome of the bladder. Thus, although detrusor overactivity may remain, contractions in the filling phase do not result in a rise in detrusor pressure sufficient to cause leakage. However, subsequent complications that may arise include inadequate emptying resulting in recurrent urinary tract infections, urinary retention, mucous accumulation and stones, electrolyte imbalance, and rarely, malignant change. Not all patients are candidates for augmentation cystoplasty, and the possibility of the need for lifetime clean intermittent catheterization must be discussed with the patient prior to the consideration of surgery. The potential complications ensure that surgical procedures are reserved for severe cases of urge incontinence that have been resistant to conservative therapy ${ }^{64}$.

Auto-augmentation refers to a type of cystoplasty that involves excision of a large portion of detrusor muscle with preservation of the underlying mucosa (detrusor myomectomy). This procedure allows a bladder diverticulum to form with consequent increase in capacity ${ }^{64}$. The procedure avoids the morbidity associated with bowel resection and incorporation of bowel in the urinary tract, but there is far from unanimous agreement that the results approach those of enterocystoplasty.

Potentially promising new therapies are on the horizon for the OAB. Currently under development are a number of pharmaceutical agents, including monoamine reuptake inhibitors, antimuscarinic agents, and intravesical agents that decrease afferent input, such as capsaicin and capsaicin-like agents, which may herald a new therapeutic paradigm for treatment of the OAB. Refinements in the technique and the delivery vehicle for electrical stimulation may offer an even less in- 
vasive method of neuromodulation. Finally, ongoing research in biotechnology and tissue engineering may produce a functional, stable, compatible tissue substitute suitable for bladder augmentation that is produced entirely in the laboratory, thereby precluding the need for bowel interposition in the urinary tract and its attendant morbidity $^{65-70}$.
ROVNER ES e col. - Avaliação e tratamento da bexiga hiperativa. Rev. Hosp. Clín. Fac. Med. S. Paulo 57(1):39-48, 2002.

A bexiga hiperativa é caracterizada pelos sintomas de frequiência, urgência e urge-incontinência e afeta de forma significativa o estilo de vida de milhões de pessoas em todo o mundo. Os sintomas são responsáveis por problemas nas esferas social, psicológica, ocupacional, doméstica, física e sexual dos pacientes. Apesar do considerável impacto desta condição sobre a qualidade de vida, grande parte dos pacientes reluta em discutir o problema com membros da família ou profissionais de saúde. Esta situação é lamentável, já que existem muitas maneiras de aliviar os sintomas da hiperatividade vesical. Por essa razão, é fundamental que se aprimore a educação médica sobre os sintomas de hiperatividade vesical e outros problemas relacionados, de modo a preparar os profissionais de saúde a identificar e tratar os pacientes com esta condição. Este artigo é uma revisão dos conceitos atuais, definição, epidemiologia, efeitos sobre a qualidade de vida, avaliação e tratamento da bexiga hiperativa.

DESCRITORES: Bexiga. Incontinência urinária. Urodinâmica.

\section{REFERENCES}

1. OVERACTIVE Bladder and its Treatments Consensus Conference. London, United Kingdom, July 4, 1999. Urology 2000;55:1-84.

2. THE Overactive Bladder: From Basic Science to Clinical Management Consensus Conference. Proceedings. London, England, June 29, 1997. Urology 1997; 50:1-114.

3. WEIN AJ \& ROVNER ES - The overactive bladder: an overview for primary care health providers. Int J Fertil Womens Med 1999; 44:56-66.

4. BOSCH JL - The overactive bladder: current aetiological concepts. BJU Int 1999; 83 (Suppl 2):7-9.

5. ARTIBANI W - Diagnosis and significance of idiopathic overactive bladder. Urology 1997; 50:25-32.

6. PAYNE CK - Epidemiology, pathophysiology, and evaluation of urinary incontinence and overactive bladder. Urology 1998; 51:310.

7. SULLIVAN $\mathrm{J} \&$ ABRAMS $\mathrm{P}$ - The overactive bladder: neuropharmacological basis of clinical management. Curr Opin Obstet Gynecol 1999; 11:477-483.
8. ABRAMS P, BLAIVAS JG, STANTON SL et al. - The standardisation of terminology of lower urinary tract function. The International Continence Society Committee on Standardisation of Terminology. Scand J Urology Nephrol 1988; 114:5-19.

9. HAMPEL C, WIENHOLD D, BENKEN C et al. - Definition of overactive bladder and epidemiology of urinary incontinence. Urology 1997; 50:4-14.

10. HAMPEL C, WIENHOLD D, BENKEN N et al. - Prevalence and natural history of female incontinence. Eur Urol 1997; 32(Suppl 2):3-12.

11. ABRAMS P \& WEIN AJ - The overactive bladder: A widespread but treatable condition. Stockholm, Sparre Medical Group, 1998.

12. DIOKNO AC - Epidemiology and psychosocial aspects of incontinence. Urol Clin North Am 1995; 22:481-485.

13. DUBEAU CE, LEVY B, MANGIONE CM et al. - The impact of urge urinary incontinence on quality of life: importance of patients' perspective and explanatory style. J Am Geriatr Soc 1998; 46:683692. 
14. JACKSON S - The patient with an overactive bladder-symptoms and quality- of-life issues. Urology 1997; 50:18-22.

15. TEMML C, HAIDINGER G, SCHMIDBAUER J et al. - Urinary incontinence in both sexes: prevalence rates and impact on quality of life and sexual life. Neurourol Urodyn 2000; 19:259-271.

16. WYMAN JF, HARKINS SW, CHOI SC et al. - Psychosocial impact of urinary incontinence in women. Obstet Gynecol 1987; 70:378381 .

17. GIRMAN CJ, JACOBSEN SJ, TSUKAMOTO T et al. - Health-related quality of life associated with lower urinary tract symptoms in four countries. Urology 1998; 51:428-436.

18. KOBELT-NGUYEN G, JOHANNESSON M, MATTIASSON A et al. - Correlations between symptoms of urge incontinence and scores of a generic quality of life instrument (SF36) and health status measurements (EuroQoL) and between changes in symptoms and QoL scores. Annual Meeting, 27 ${ }^{\text {th }}$, of the International Continence Society 1997; September 23-27.

19. KOBELT G, KIRCHBERGER I \& MALONE LJ - Review. Qualityof-life aspects of the overactive bladder and the effect of treatment with tolterodine. BJU Int 1999; 83:583-590.

20. FITZGERALD ST, PALMER MH, BERRY SJ et al. - Urinary incontinence. Impact on working women. AAOHN 2000; 48:112118 .

21. WAGNER TH \& HU TW - Economic costs of urinary incontinence in 1995. Urology 1998; 51:355-361.

22. BRADING AF - A myogenic basis for the overactive bladder. Urology 1997; 50:57-67.

23. DE GROAT WC - A neurologic basis for the overactive bladder. Urology 1997; 50:36-52.

24. TURNER WH \& BRADING AF - Smooth muscle of the bladder in the normal and the diseased state: pathophysiology, diagnosis and treatment. Pharmacol Ther 1997; 75:77-110.

25. ELBADAWI A, YALLA SV \& RESNICK NM - Structural basis of geriatric voiding dysfunction. III. Detrusor overactivity. J Urol 1993; 150:1668-1680.

26. ELBADAWI A - Pathology and pathophysiology of detrusor in incontinence. Urol Clin North Am 1995; 22:499-512.

27. ABRAMS PH, FARRAR DJ, TURNER WR et al. - The results of prostatectomy: a symptomatic and urodynamic analysis of 152 patients. J Urol 1979; 121:640-642.

28. ANDERSEN JT - Prostatism. III. Detrusor hyperreflexia and residual urine. Clinical and urodynamic aspects and the influence of surgery on the prostate. Scand J Urol Nephrol 1982; 16:25-30.

29. BLAIVAS JG - Pathophysiology and differential diagnosis of benign prostatic hypertrophy. Urology 1988; 32:5-11.

30. CUCCHI A - Detrusor instability and bladder outflow obstruction. Evidence for a correlation between the severity of obstruction and the presence of instability. Br J Urol 1988; 61:420-422.

31. I CONSENSO Brasileiro - Incontinência urinária, Uroneurologia e disfunções miccionais. Sao Paulo, BG Cultural, 1999.
32. FANTL JA, NEWMAN DK, COLLING J et al. - Urinary incontinence in adults: Acute and chronic management. Rockville,MD: U.S. Department of Health and Human Services., Public Health Service, Agency for Health Care Policy and Research., 1996.

33. BLAIVAS JG - Outcome measures for urinary incontinence. Urology 1998; 51:11-19.

34. NWOSU CR, KHAN KS, CHIEN PF et al. - Is real-time ultrasonic bladder volume estimation reliable and valid? A systematic overview. Scand J Urol Nephrol 1998; 32:325-330.

35. ALNAIF B \& DRUTZ HP - The accuracy of portable abdominal ultrasound equipment in measuring postvoid residual volume. Int Urogynecol J Pelvic Floor Dysfunct 1999; 10:215-218.

36. ANDERSSON KE - The overactive bladder: pharmacologic basis of drug treatment. Urology 1997; 50:74-84.

37. BO K \& BERGHMANS LC - Nonpharmacologic treatments for overactive bladder-pelvic floor exercises. Urology 2000; 55:7-11.

38. BRUBAKER L - Electrical stimulation in overactive bladder. Urology 2000; 55:17-23.

39. WEIN AJ - Pharmacologic options for the overactive bladder. Urology 1998; 51:43-47.

40. CARDOZO LD - Biofeedback in overactive bladder. Urology 2000; 55:24-28.

41. PAYNE CK - Behavioral therapy for overactive bladder. Urology 2000; 55:3-6.

42. FANTL JA, WYMAN JF, MCCLISH DK et al. - Efficacy of bladder training in older women with urinary incontinence. JAMA 1991; 265:609-613.

43. FANTL JA - Behavioral intervention for community-dwelling individuals with urinary incontinence. Urology 1998; 51:30-34.

44. BURGIO KL, LOCHER JL, GOODE PS et al. - Behavioral vs drug treatment for urge urinary incontinence in older women: a randomized controlled trial. JAMA 1998; 280:1995-2000.

45. CHAPPLE CR - Muscarinic receptor antagonists in the treatment of overactive bladder. Urology 2000; 55:33-46.

46. ANDERSSON KE - The overactive bladder: pharmacologic basis of drug treatment. Urology 1997; 50:74-84.

47. WEIN AJ - Neuromuscular Dysfunction of the Lower Urinary Tract and its treatment. In: WALSH PC, RETIK AB, VAUGHAN EDJR et al. (Eds.) - Campbell's Urology. Philadelphia, Saunders, 1998. p.953-1006.

48. KELLEHER CJ, CARDOZO LD, KHULLAR V et al. - A mediumterm analysis of the subjective efficacy of treatment for women with detrusor instability and low bladder compliance. Br J Obstet Gynaecol 1997; 104:988-993.

49. ABRAMS P, FREEMAN R, ANDERSTRÖM C et al. - Tolterodine, a new antimuscarinic agent: as effective but better tolerated than oxybutynin in patients with an overactive bladder. Br J Urol 1998; 81:801-810.

50. APPELL RA - Clinical efficacy and safety of tolterodine in the treatment of overactive bladder: a pooled analysis. Urology 1997; 50:90-96. 
51. DRUTZ HP, APPELL RA, GLEASON D et al. - Clinical efficacy and safety of tolterodine compared to oxybutynin and placebo in patients with overactive bladder. Int Urogynecol J Pelvic Floor Dysfunct 1999; 10:283-289.

52. CARDOZO LD \& KELLEHER CJ - Sex hormones, the menopause and urinary problems. Gynecol Endocrinol 1995; 9:75-84.

53. FANTL JA, BUMP RC, ROBINSON D et al. - Efficacy of estrogen supplementation in the treatment of urinary incontinence. The Continence Program for Women Research Group. Obstet Gynecol 1996; 88:745-749.

54. KARRAM MM, PARTOLL L \& RAHE J - Efficacy of nonsurgical therapy for urinary incontinence. J Reprod Med 1996; 41:215219.

55. ULMSTEN U - Some reflections and hypotheses on the pathophysiology of female urinary incontinence. Acta Obstet Gynecol Scand 1997; 166:3-8.

56. SIEGEL SW, RICHARDSON DA, MILLER KL et al. - Pelvic floor electrical stimulation for the treatment of urge and mixed urinary incontinence in women. Urology 1997; 50:934-940.

57. FALL M - Advantages and pitfalls of functional electrical stimulation. Acta Obstet Gynecol Scand 1998; 168:16-21.

58. BO K - Effect of electrical stimulation on stress and urge urinary incontinence. Clinical outcome and practical recommendations based on randomized controlled trials. Acta Obstet Gynecol Scand 1998; 168 Suppl:3-11.

59. APPELL RA - Electrical stimulation for the treatment of urinary incontinence. Urology 1998; 51:24-26.

60. VAN KERREBROECK PE - The role of electrical stimulation in voiding dysfunction. Eur Urol 1998; 34 Suppl 1:27-30.
61. BOSCH JL \& GROEN J - Sacral nerve neuromodulation in the treatment of patients with refractory motor urge incontinence: longterm results of a prospective longitudinal study. J Urol 2000 ; 163:1219-1222.

62. RUUD BJ \& GROEN J - Treatment of refractory urge urinary incontinence with sacral spinal nerve stimulation in multiple sclerosis patients. Lancet 1996; 348:717-719.

63. SHAKER HS \& HASSOUNA M - Sacral nerve root neuromodulation: an effective treatment for refractory urge incontinence. J Urol 1998; 159:1516-1519.

64. APPELL RA - Surgery for the treatment of overactive bladder. Urology 1998; 51:27-29.

65. KIM BS, BAEZ CE \& ATALA A - Biomaterials for tissue engineering. World J Urol 2000; 18:2-9.

66. OBERPENNING F, MENG J, YOO JJ et al. - De novo reconstitution of a functional mammalian urinary bladder by tissue engineering. Nat Biotechnol 1999; 17:149-155.

67. ATALA A - Engineering tissues and organs. Curr Opin Urol 1999; 9:517-526.

68. CHENG EY \& KROPP BP - Urologic tissue engineering with smallintestinal submucosa: potential clinical applications. World J Urol 2000; 18:26-30.

69. KERSHEN RT, FEFER SD \& ATALA A - Tissue-engineered therapies for the treatment of urinary incontinence and vesicoureteral reflux. World J Urol 2000; 18:51-55.

70. DESGRANDCHAMPS F \& GRIFFITH DP - The artificial bladder. Eur Urol 1999; 35:257-266.

Received for publication on March 20, 2001 